\title{
Low Fatigue Strength of Clinch Joints
}

\author{
Tadeusz Balawender \\ The Faculty of Mechanical Engineering and Aeronautics, Rzeszow University of Technology, Rzeszów 35-959, Poland
}

\begin{abstract}
Clinching can be used for effective joining of different metallic materials, e.g., different grades of carbon and alloy steels, aluminum and its alloys and others. This is an alternative joining method to traditional methods involving screws, rivets or welding. Clinching is applied in many fields of manufacturing industry. Future applications of clinch joining require advances in quality and among others things, combination with other processes, e.g., hybrid joining by clinching and adhesive bonding. Although the static strength of clinched joints is lower than that of the others joints (e.g., pressure welded joints), the fatigue strength is comparable. But there is a lack of information about fatigue strength of clinched joints. The static and low cyclic fatigue strengths of mechanically clinched joints were determined experimentally. The load-displacement curves of static strength were compared with low cyclic fatigue strength curves. It was observed the effect of strain hardening for clinched joint of low carbon steels (DC4) under cyclic loading.
\end{abstract}

Key words: Clinching, mechanical joining, sheet metal joining, static and fatigue strength.

\section{Introduction}

Clinching is an alternative joining method of sheet metals without the use of heat, rivets, fasteners or adhesives [1-4]. Riveting and screwing need a previous punching or drilling of sheets, welding causes localized heating, what leads to changes in the mechanical properties of materials. During clinching sheet metal parts are deformed locally with a punch and a die; the squeezed material flows outward and an interlock is formed between the joined parts. The method is used to joining sheets of thickness between 0.2 and $4 \mathrm{~mm}$ and both sheets are not required to be the same kind of material and equal thickness [2, 4]. It is very good method for fastening galvanized, pre-painted and coated aluminum, mild steel, stainless steel as well as brass and copper.

The properties of joined materials are very important for the clinch joint strength. The geometry of forming tools should be matched to the mechanical properties of joined materials. The shearing strength of clinch joints obtained for pairs of different materials, made with the same clinching tools are related to material arrangement during clinching [5]. For the same pair of

Corresponding author: Tadeusz Balawender, D.Sc., research field: metalworking. materials two different values of shear strength are obtained. The strength of joint is higher when the "stronger" material is on the punch side and the "weaker" on the die side, e.g., compare strength of aluminum-steel and steel-aluminum joints.

Clinching is applied in automobile industry (particularly in certain parts of the vehicle body (as shown in Fig. 1) and in furniture and computer industries, in different kind household appliances as well as in ventilation and air conditioning systems [1].

However, a prospective application of this technology in automobile and especially in aerospace requires more attention $[3,6]$.

As it can be seen in Fig. 2, clinching involves strong local plastic deformation of two (or more) sheet metal parts and the proper description of this process should include: tool geometries, parameter optimization and FEA simulation of the process [5, 7-11]. The metal flow during clinching process is limited to a very small region around the tools; there is almost no flow of the material outside the clinched region towards the joint [6]. As it was shown in Ref. [7], the strain-hardening exponent $n$ of sheet material can be used as ability to clinching criterion; high value of strain-hardening exponent $\mathrm{n}$ is not favorable for clinch joint forming; the clinch joints of high strength were manufactured when 


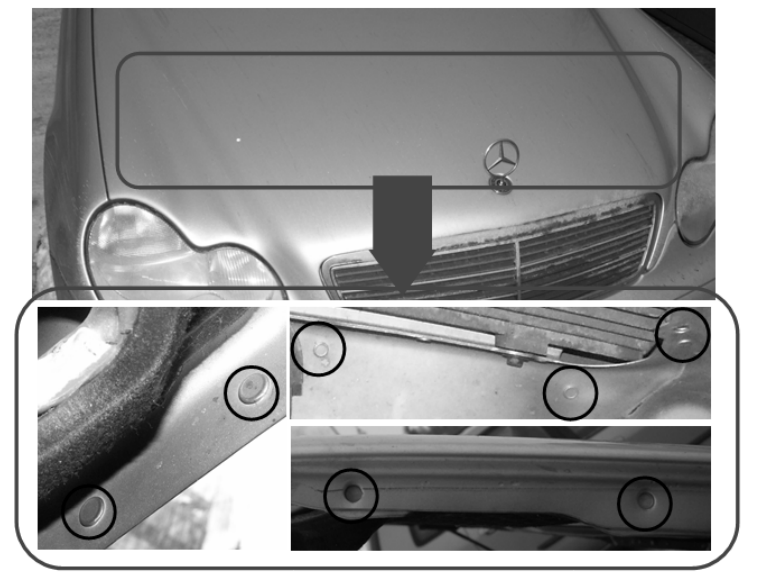

Fig. 1 Clinch joints (marked by the circles) in a car bonnet.

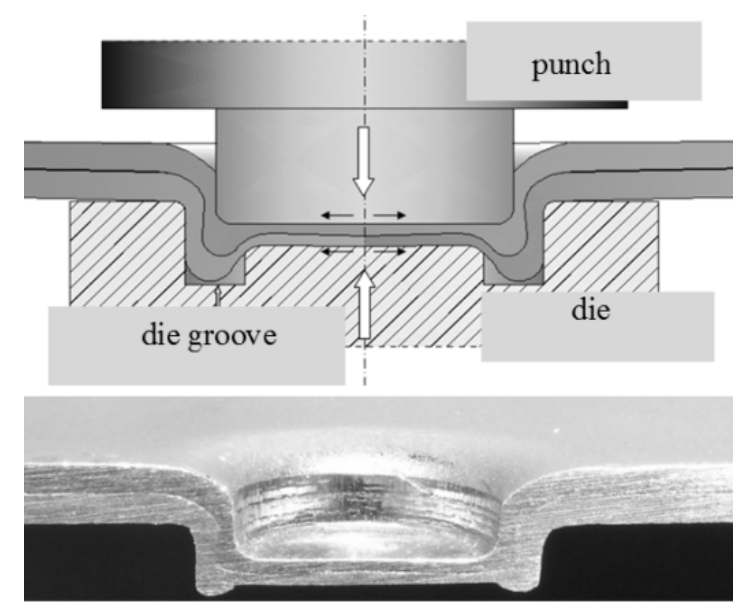

Fig. 2 Scheme of the clinching process and a picture of longitudinal section of steel-copper clinch joint.

low values strain-hardening exponent materials were clinched. Very important for clinching process are friction conditions on the joined sheets interface [7]. The clinched joint strength is strongly related to the interface mechanical adhesion between joined sheets, not only to the joint geometrical parameters and joined material properties.

The main geometrical parameters of the clinch joint are: the axial thickness of the sheets denoted by " $x$ ", the thinning of the upper sheet denoted by "th" (also called the neck or nick thickness) and the clinch lock denoted by "cl" (Fig. 3). The force necessary to separate the sheets is very important parameter of the joint. It depends mainly on the neck thickness and on the undercut. Thin necks lead to sheet separations by the fracture of the upper sheet in the neck. Small undercut

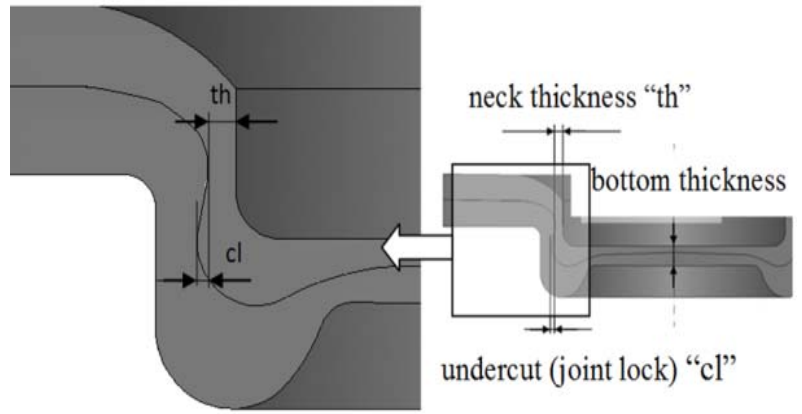

Fig. 3 Clinch joint parameters.

leads to low separating forces, caused by the vertical sliding apart of the two sheets.

The strength of the proper clinch joint is determined by the amount of formed interlock between sheets but this strength is not high in comparison with other joining methods, e.g., spot welding [11, 12]. This resistance to shear or tensile loading can be one-half to three-fourth lower than the equivalent size of spot welding joint [8]. The mechanical strength is closely related to the final geometry of the clinch joint. So, it is important to understand the relation between the clinching process parameters (tool geometry, applied loads, lubrication), obtained the joint parameters, mainly its geometry (neck thickness, undercut, bottom thickness) and its mechanical strength.

The static strength of clinched joints is lower than that of other joints (e.g., pressure welded joints) but the fatigue strength is comparable [3, 8]. During cyclic loading within the elastic regime, stress and strain are directly related through the elastic modulus. For cyclic loading that produces plastic strains, the load-displacement responses are more complex and form a hysteresis loop. The area of the hysteresis loop is equal to the work done or the energy loss per cycle [13]. Fatigue is recognized to be the principal cause of many mechanical failures. Complex geometrical structures are often involved and complex multiaxial loadings are occurring. Low cycle fatigue, in contrast to high cycle fatigue, is generally characterized by failure in less than $10^{4}$ cycles showing a pronounced plastic mechanical response. These loading conditions can occur in automobile or especially in airplane 
structures during or after unpredictable mechanical impacts, e.g., hard landing, bad weather conditions, operational errors, failure of structural integrity [14].

\section{Experimental Procedure}

In order to estimate the mechanical strength of clinched joints the tensile - shear tests were performed. All clinch indentations were manufactured using the same tools; the outer diameter of the joint convexity was equal $10 \mathrm{~mm}$. Material of joined sheets was low carbon steel grade DC4 and sheet thickness was $1 \mathrm{~mm}$. The overlap specimens with one-point clinched joint were tensile - shear loaded (pull test) in static and low cycle fatigue tests. Specimens were subjected to tensile tests and fatigue tests (stress ratio $\mathrm{R}=\sigma_{\min } / \sigma_{\max } \approx 0$ and amplitude ratio $\mathrm{A}=\sigma_{\mathrm{a}} / \sigma_{\mathrm{m}} \approx 1$, where $\sigma_{\mathrm{a}}=\left(\sigma_{\max }-\right.$ $\left.\left.\sigma_{\min }\right) / 2, \sigma_{\mathrm{m}}=\left(\sigma_{\max }+\sigma_{\min }\right) / 2\right)$, using a universal testing machine Zwick-Roell with maximum nominal load equal to $100 \mathrm{kN}$. Fatigue tests were performed with load controlled process; the load amplitude was held constant. The displacement amplitude was changeable (Fig. 4).

\section{Experimental Results}

Specimen loaded by max. load equal $4 \mathrm{kN}$ sustained 187 cycles. It is great number of cycles if take into account the mean static strength of the joint equal 4.17 kN (Fig. 5).

When testing these joints with maximal load $3.5 \mathrm{kN}$ they sustain over 1,000 cycles (Fig. 6). And when in 1,001 cycle loading such joint up to failure, the maximal load was equal about $4.9 \mathrm{kN}$, what means $18 \%$ growth of static loading $\mathrm{F}_{\max }$. This strain hardening phenomenon can be a result of cyclic strain hardening of clinch joint. As it was shown in Ref. [13], strong metals tend to cyclically soften, and low-strength metals tend to cyclically harden. However, the hysteresis loop tends to stabilize after a few hundred cycles, when the material attains a stable condition for the imposed load level.

There are differences in failure mode in static and fatigue tests. In static tensile-shear test the joint opens as a press-stud fastener (Fig. 7a) and in fatigue test the failure occurs as a breakage in the joint neck (Fig. 7b).

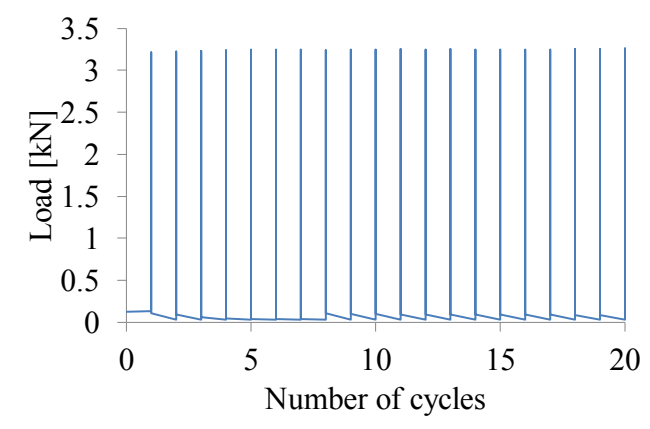

(a)

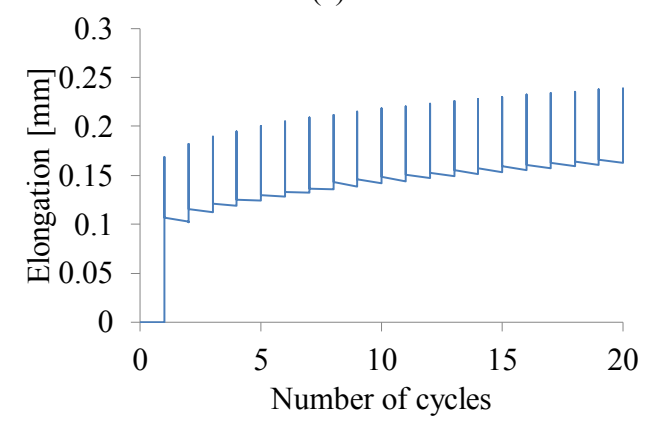

(b)

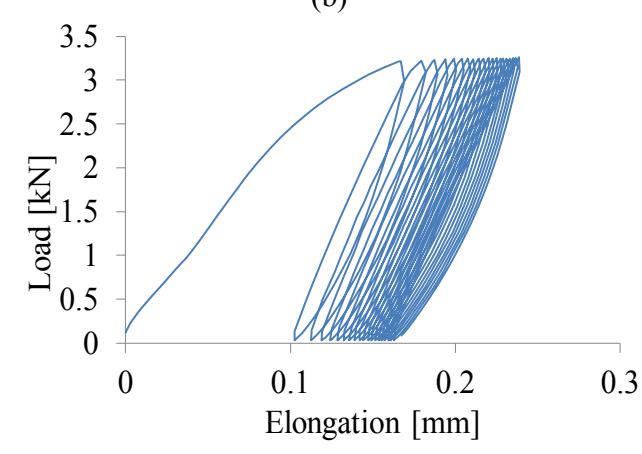

(c)

Fig. 4 Load (a) and elongation (b) versus number of cycles and load-elongation hysteresis loops (c) for cyclic loading $\left(F_{\text {max }}=3,250 \mathrm{~N}\right.$, number of cycles-20).

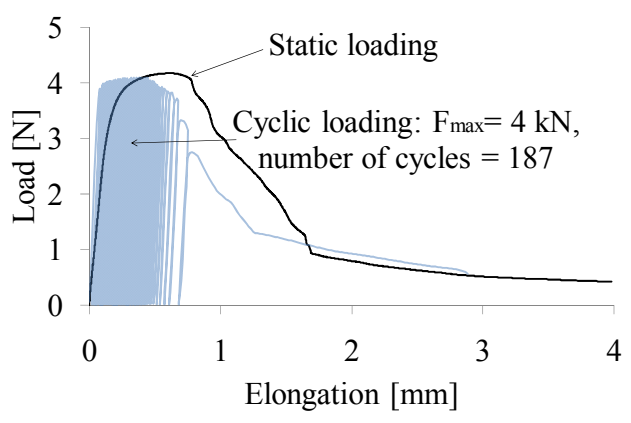

Fig. 5 Tensile test results: static and fatigue elongation-load response of DC4 steel sheet clinched joint. 


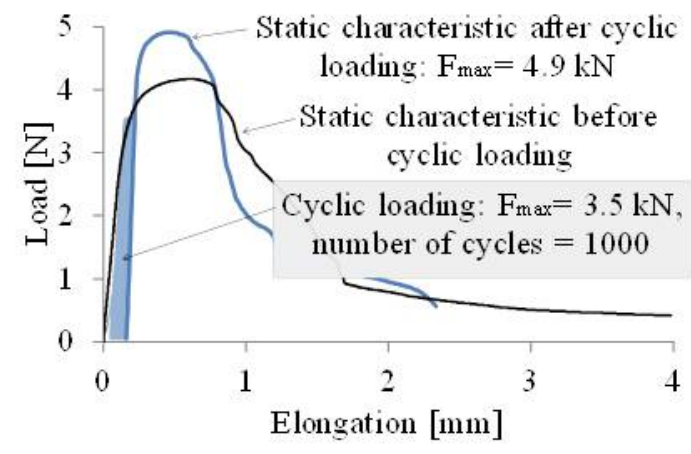

Fig. 6 Strain hardening of clinched joint of DC4 steel sheets observed after cyclic loading $\left(F_{\max }=3.5 \mathrm{kN}\right.$, number of cycles $=1,000$ ).

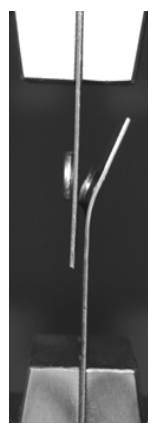

(a)

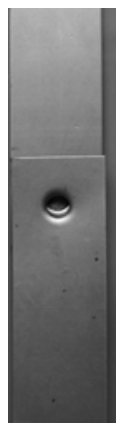

(b)

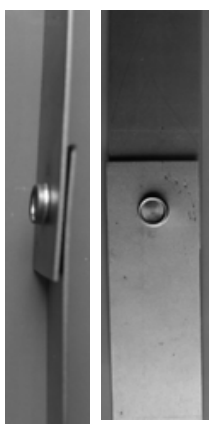

Fig. 7 Failure under the tensile-shear static loading (a) static loading and (b) cyclic loading.

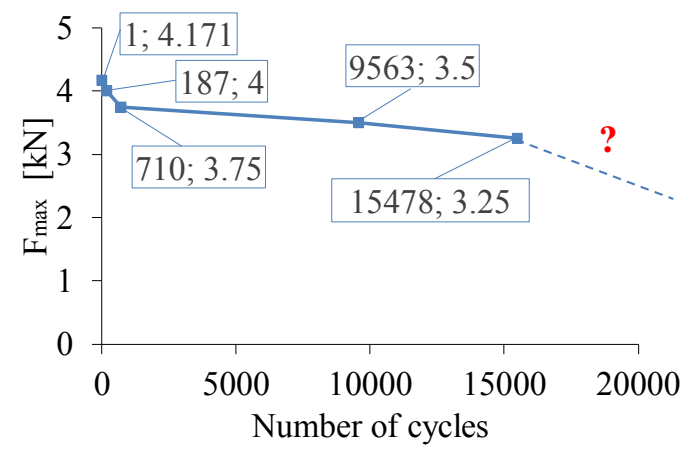

Fig. 8 Low-cyclic fatigue live of DC4 steel clinch joint.

The investigations covered four cyclic tests with maximal load equal respectively: $4,3.75,3.5,3.25 \mathrm{kN}$, as it is shown in Fig. 8, as a low-cyclic fatigue characteristic. The number of cycles varied in the range from 4 to 15,478, when impose different load levels. What happens with greater number of cycles? The answer needs high-cycle fatigue investigations.

\section{Conclusions}

Clinch joints of low carbon steel sheets are characterized by very good low-cycle fatigue strength. Such joints undergo strain hardening law when cyclic loading. It was observed about $18 \%$ growth of static loading after low-cyclic loading of DC4 steel sheets clinch joints. The differences in failure mode of clinched joints are observed in static tensile test (the joint opens as a press-stud fastener) and cyclic tensile test (the joint failures by cracks in the joint neck).

\section{Acknowledgment}

Financial support of Structural Funds in the IEOP (Operational Program-Innovative Economy) financed from the European Regional Development Fund-Project "Modern material technologies in aerospace industry", No. POIG.0101.02-00-015/08 is gratefully acknowledged, Task 15-Unconventional technologies of joining elements of aeronautical constructions.

\section{References}

[1] Varis, J. P., and Lepisto, J. 2003. "A Simple Testing-based Procedure and Simulation of the Clinching Process Using Finite Element Analysis for Establishing Clinching Parameters." Thin Walled Struct 41 (8): 691-709.

[2] Barnes, T. A., and Pashby, I. R. 2000. "Joining Techniques for Aluminium Spaceframes Used in Automobiles: Part II Adhesive Bonding and Mechanical Fasteners." Journal of Materials Processing Technology 99 (1): 72-9.

[3] Varis, J. 2006. "Ensuring the Integrity in Clinching Process." Journal of Materials Processing Technology 174 (1-3): 277-85.

[4] He, X. 2010. "Recent Development in Finite Element Analysis of Clinched Joints." Int. J. Adv. Manuf. Technol. 48 (5-8): 607-12.

[5] Sadowski, T., and Balawender, T. 2011. "Technology of Clinch-Adhesive Joints, in Hybrid Adhesive Joints." In Advanced Structured Materials, Vol. 6, edited by da Silva, L. F. M., Pirondi, A., and Öschner, A. Springer, 149-76.

[6] Gronostajski, Z., and Polak, S. 2008. "Zastosowanie metod klinczowania do łączenia profili cienko-ściennych stosowanych w kontrolowanych strefach zgniotu." Presented at the 17th International Scientific and Technical Conference "Design And Technology of Drawpieces and Die Stampings", Poznań-Wąsowo, Poland. 
[7] Sadowski, T., Balawender, T., and Golewski, P. 2015. Technological Aspects of Manufacturing and Numerical Modelling of Clinch-Adhesive Joints, SpringerBriefs in Applied Sciences and Technology, Springer.

[8] Carboni, M., Beretta, S., and Monno, M. 2006. "Fatigue Behaviour of Tensile-Shear Loaded Clinched Joints." Engineering Fracture Mechanics 73: 178-90.

[9] Jayasekara, V., Min, K. H., Noh, J. H., Kim, M. T., Seo, J. M., Lee, H. Y., and Hwang, B. B. 2010. "Rigid-Plastic and Elastic-Plastic Finite Element Analysis on the Clinching Joint Process of Thin Metal Sheets." Metals and Materials International 16 (2): 339-47.

[10] Lee, C. J., Kim, J. Y., Lee, S. K., Ko, D. C., and Kim, B. M. 2010. "Design of Mechanical Clinching Tools for Joining of Aluminium Alloy Sheets." Materials Design
31: 1854-61.

[11] Oudjene, M., and Ben-Ayed, L. 2008. "On the Parametrical Study of Clinch Joining of Metallic Sheets Using the Taguchi Method." Engineering Structures 30: 1782-8.

[12] De Paula, A. A., Aguilar, M. T. P., Pertence, A. E. M., and Cetlin, P. R. 2007. "Finite Element Simulations of the Clinch Joining of Metallic Sheets." Journal of Materials Processing Technology 182: 352-7.

[13] Campbell, F. C. 2008. Elements of Metallurgy and Engineering Alloys, ASM International.

[14] Vyshnevskyy, A., Khan, S., and Mosler, J. 2009. "Low Cycle Lifetime Prediction of Al2024 Alloy." Presented at the 25th ICAF Symposium, Rotterdam, the Netherlands. 